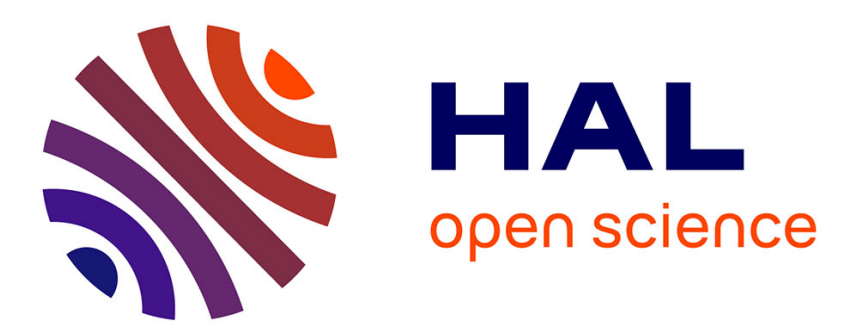

\title{
Improving the fatigue life of aeronautical single-lap bolted joints thanks to the hybrid (bolted/bonded) joining technology
}

Eric Paroissien, Cat-Tan Hoang-Ngoc, Harvind Bhugaloo, David Ducher

\section{- To cite this version:}

Eric Paroissien, Cat-Tan Hoang-Ngoc, Harvind Bhugaloo, David Ducher. Improving the fatigue life of aeronautical single-lap bolted joints thanks to the hybrid (bolted/bonded) joining technology. 25th ICAF Symposium, May 2009, Rotterdam, Netherlands. pp. 475-492. hal-01515373

\author{
HAL Id: hal-01515373 \\ https://hal.science/hal-01515373
}

Submitted on 27 Apr 2017

HAL is a multi-disciplinary open access archive for the deposit and dissemination of scientific research documents, whether they are published or not. The documents may come from teaching and research institutions in France or abroad, or from public or private research centers.
L'archive ouverte pluridisciplinaire HAL, est destinée au dépôt et à la diffusion de documents scientifiques de niveau recherche, publiés ou non, émanant des établissements d'enseignement et de recherche français ou étrangers, des laboratoires publics ou privés. 


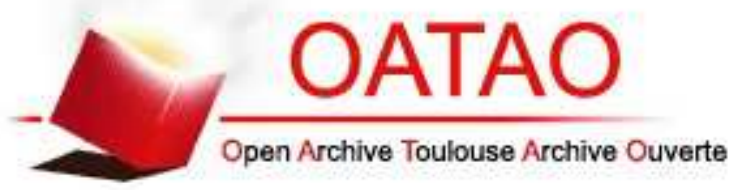

\section{Open Archive Toulouse Archive Ouverte (OATAO)}

OATAO is an open access repository that collects the work of Toulouse researchers and makes it freely available over the web where possible.

This is an author version published in: http://oatao.univ-toulouse.fr/ Eprints ID: 17646

To cite this version: Paroissien, Eric and Hoang-Ngoc, Cat-Tan and Bhugaloo, Harvind and Ducher, David Improving the fatigue life of aeronautical single-lap bolted joints thanks to the hybrid (bolted/bonded) joining technology. (2009) In: 25th ICAF Symposium, 27 May 2009 - 29 May 2009 (Rotterdam, Netherlands).

Official URL: http://dx.doi.org/10.1007/978-90-481-2746-7_27

Any correspondence concerning this service should be sent to the repository administrator: staff-oatao@ listes-diff.inp-toulouse.fr 


\title{
IMPROVING THE FATIGUE LIFE OF
}

\author{
AERONAUTICAL SINGLE-LAP \\ BOLTED JOINTS THANKS TO THE \\ HYBRID (BOLTED/BONDED) JOINING \\ TECHNOLOGY \\ E. Paroissien ${ }^{1}$, C.T. Hoang Ngoc ${ }^{1}$, H. Bhugaloo ${ }^{1}$, D. Ducher ${ }^{1}$ \\ ${ }^{1}$ SOGETI HIGH TECH, PE3, Department of Fatigue and \\ Damage Tolerance, Blagnac, France
}

\begin{abstract}
It has been experimentally shown [1-5] the possibility to obtain with hybrid (bolted/bonded) joining technology higher static failure load and a longer fatigue life than the corresponding bolted or bonded joints by using a suitable adhesive.
\end{abstract}


This paper aims at comprehensively showing, by both a simplified analytical approach and an accurate three-dimensional finite element analysis that the application of hybrid (bolted/bonded) joining technology instead of the classical bolted technology allows for a possible improvement of fatigue life.

A simplified theoretical analysis is presented to understand the mechanical behaviour of such joints and to provide possible elastic mechanical properties of a suitable adhesive. Then, an accurate three-dimensional Finite Element model is developed to demonstrate the possible benefit on fatigue life.

\section{INTRODUCTION}

In the frame of aircraft performance efficiency enhancement both by reducing manufacturing costs and increasing weight saving, the design of longitudinal metallic joints of civil aircraft is under consideration. These joints are mainly singlelap bolted joints, the criterion of design of which is the fatigue strength. Moreover, between jointed sheets, a layer of sealant is applied to ensure the sealing of the pressurized cabin and the protection against galvanic corrosion.

Hybrid (bolted/bonded) - quoted HBB - joining technology allows for associating a discrete transfer mode with a continuous transfer mode, each one having its own 
stiffness. The bolted system (discrete transfer mode) generates a high stress concentration around the holes, which is penalising to the fatigue strength. The bonded part allows a better distribution of the load transfer between the adherends. In regard to aircraft assembly, HBB joining could be interesting because it could reduce the load transferred by the fasteners to improve the fatigue life, while ensuring the static strength under extreme loads.

HBB joining technology was presented as a relevant concept of fail-safe structures by Hart-Smith [6] in 1982. According to this study, HBB joints with aerospace configurations and material systems do not offer any significant increase in strength compared to bonded joints, which could be explained by the low fraction of load transferred by the fasteners. In 1995, Imanaka [1] showed that the fatigue strength of bonded joints can be improved through the combination with a rivet. Since 2000, along with the development of adhesive materials as well as the increasing use of composite structures in industrial applications, some studies have been pursued to analyse the mechanical performance of $\mathrm{HBB}$ joints. $\mathrm{Fu}$ and Mallick [2] experimentally demonstrated that single-lap HBB joints with structural injection moulded (SRIM) composite as the adherends and epoxy material as the adhesive possess a higher static strength and longer fatigue life as the corresponding bonded joints. Kelly [3,4] or Paroissien [5] experimentally showed that as the load can be shared between the adhesive and the bolt by using low modulus adhesive, HBB joints can have greater static strength and fatigue life than the corresponding bonded or bolted joints respectively. Paroissien et al. recently developed analytical onedimensional (1D) [7] and two-dimensional (2D) [8] models which allow for the 
investigation of balanced single-lap HBB joints with linear elastic material systems. It was shown that a low modulus adhesive should be used, in order to suitably distribute the load between the adhesive layer and the fasteners.

In order to demonstrate the possible benefits of HBB joining technology in fatigue life comprehensively, a reference configuration of a two fastener lines single-lap HBB joint is chosen, as illustrated in Figure 1.

The first part of this paper presents the approach employed.

The second part deals with the formulation of a 1D analytical approach, which, in particularly, allows the computation of the bolt load transfer rates.

The third part presents the accurate three-dimensional (3D) finite element (FE) model developed to understand the mechanical behaviour of HBB joints and to show the possible benefits expected in fatigue life. 


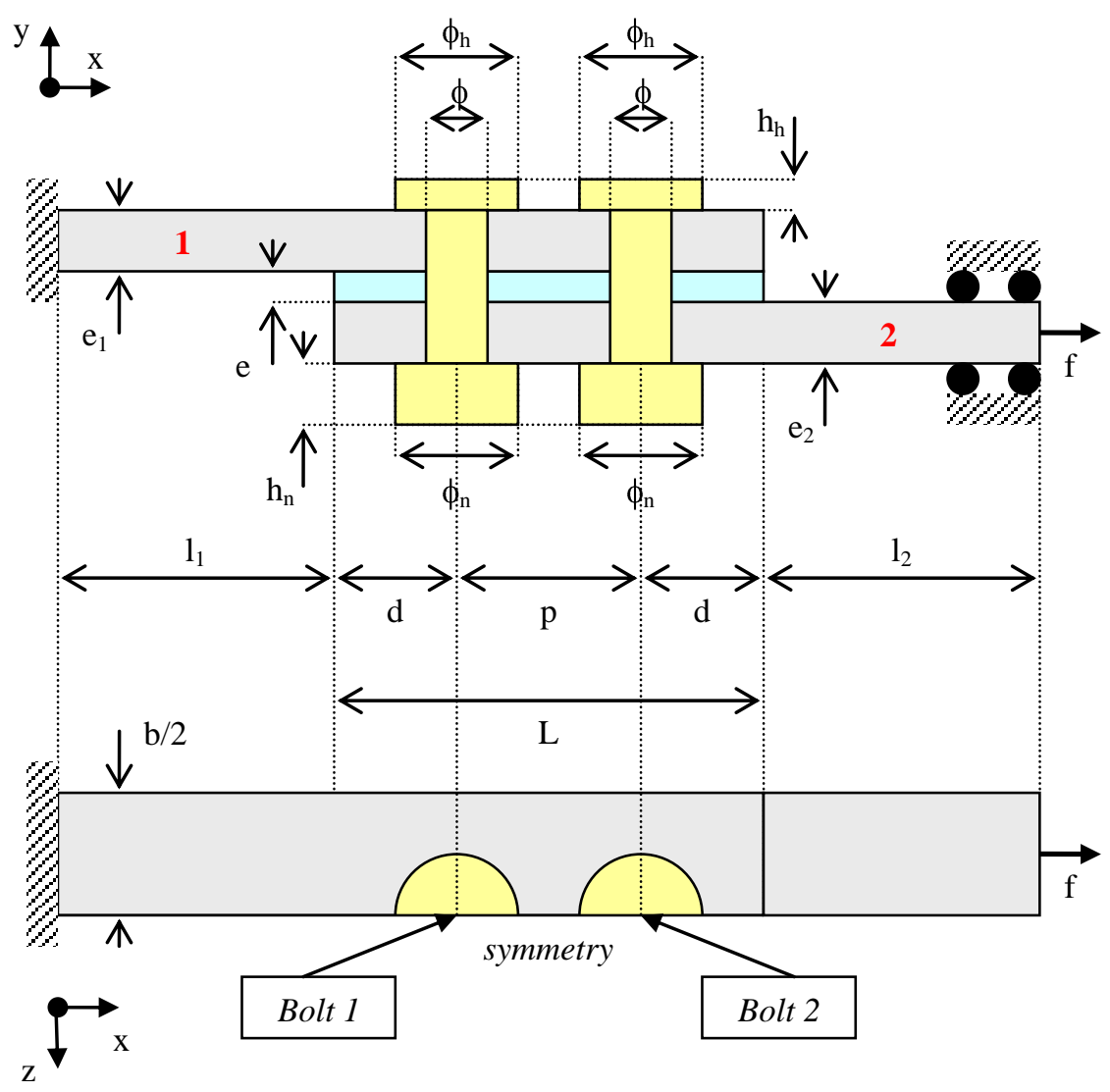

Figure 1: Reference configuration and labelling

\begin{tabular}{c|c|c|c|c|c|c|c|c|c|c|c|c|c}
\hline \hline $\mathrm{b}$ & $\mathrm{d}$ & $\mathrm{e}$ & $\mathrm{e}_{1}$ & $\mathrm{e}_{2}$ & $\mathrm{~h}_{\mathrm{h}}$ & $\mathrm{h}_{\mathrm{n}}$ & $\mathrm{L}$ & $\mathrm{l}_{1}$ & $\mathrm{l}_{2}$ & $\mathrm{p}$ & $\phi$ & $\phi_{\mathrm{h}}$ & $\phi_{\mathrm{n}}$ \\
\hline 24 & 12 & 0.1 & 1.6 & 7.2 & 10.08 & 48 & 178 & 24 & 4.8 & 1.155 & 6.6 \\
\hline \hline
\end{tabular}

Table 1: Geometrical parameters of the reference configuration in $\mathrm{mm}$ 


\begin{tabular}{c|c|c|c|c|c|c|c}
\hline \hline $\mathrm{E}_{\mathrm{f}}$ & $\mathrm{E}_{1}$ & $\mathrm{E}_{2}$ & $\mathrm{G}$ & $\mathrm{G}_{\mathrm{f}}$ & $\mathrm{G}_{1}$ & $\mathrm{G}_{2}$ & $\mathrm{~K}$ \\
\hline 110000 & 73100 & variable & 41353 & 27481 & 5000 \\
\hline \hline
\end{tabular}

Table 2: Mechanical parameters of the reference configuration in MPa

\begin{abstract}
APPROACH
In the frame of the analysis of bolted joints, the fatigue life is mainly dependent on the stress concentration factor (SCF). The lesser the SCF, the more the fatigue life is. Experimental curves in [9] show with higher stress concentration generated at the fastener holes, the fatigue life becomes lesser.
\end{abstract}

This SCF corresponds to the sum of the bypass load and the transferred load contributions. As a result, in order to increase the fatigue life of a bolted joint, it is sufficient to decrease the bolt load transfer rate, such as performed by increasing the number of the fastener lines.

Indeed, the maximum bolt load transfer rate is located at the extreme fastener lines. These extreme fastener lines represent the critical failure sites. When the number of fastener lines increase, the maximum bolt load rate transfer tends to decrease, with 
the consequence of decrease in critical SCF on the extreme fastener lines and thus fatigue life is increased.

The idea to use the HBB joining technology is to decrease the bolt load transfer and the bypass load in order to decrease the SCF, without increasing the number of fastener lines.

In order to simplify the analysis, two hypotheses $\mathrm{H} 1$ and $\mathrm{H} 2$ are considered. $\mathrm{H} 1$ consists in assuming that no preload is applied to the bolts, so that no additional stress concentration is set. H2 supposes that the adhesive layer does not fail under fatigue load, whichever the adhesive stiffness under consideration. The validity of $\mathrm{H} 2$ is referred to the adhesive strength and stiffness. In this study, the bore holes are found to be the critical sites.

The fatigue strength of the adhesive layer is not addressed in this paper. The fatigue performance analysis is then restricted to HBB joints, for which the critical zones are located at bore holes rather than at the overlap ends. The adhesive is considered to be flexible, meaning that it is able both to sustain large deformation and to have low stiffness, so that HBB joints do not fail at the overlap end regions in the adhesive as well as in the adherends.

ONE-DIMENTIONNAL ANALYTICAL ANALYSIS FOR THE BOLT LOAD TRANSFER RATE COMPUTATION 
Description of the analysis

The computation of bolt load transfers is based on an improved approach of the general method developed in details in [7] applied to the reference configuration. The improvement consists in taking into account to the adherend shear stress varying linearly with the adherend thickness.

In this study, existing one-dimensional methods for bonding is combined with bolting analysis, so that the overlap is meshed in three bays linked by both fasteners (Figure 2). Each of the three bonded bay is analysed with the help of the improved Volkersen's bonding approach [10], while the link between two consecutive bays is performed using the electrical analogy approach employed in the bolted joints analysis $[11,12]$.

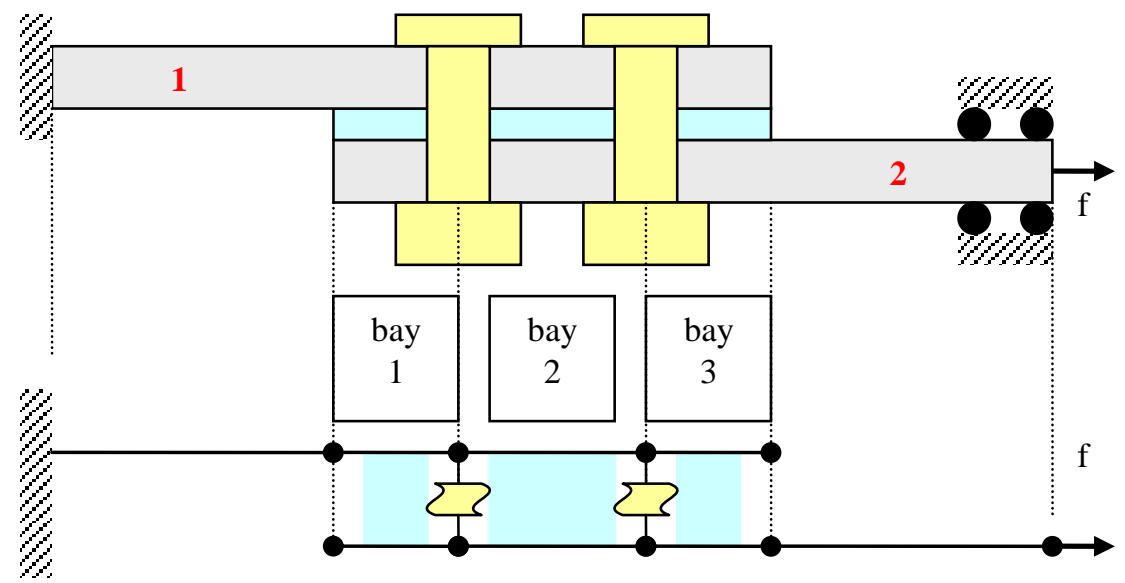


Figure 2: Meshing of the reference configuration

\section{Hypotheses}

The model is based on the following hypotheses:

- the component (adhesive, adherends, fasteners) materials are linear elastic and isotropic;

- the adhesive layer thickness is constant all along the overlap;

- the adhesive shear stress is constant through the adhesive layer thickness;

- the adherend shear stress varies linearly with the adherend thickness.

The 1D beam theory is employed, so that both adherends are simulated by unrestricted bars. Each fastener is classically simulated by a shear spring, the stiffness of which is quoted $\mathrm{C}_{\mathrm{f}}$. Finally, the adhesive layer is simulated by an infinite number of shear springs linking both adherends. In this study, it is underlined that the possible adherends bending and the adhesive peel stress are not considered in the presented model.

\section{$\underline{\text { Computation of bolt load transfer rates }}$}


The index i represents the number of a bay included between 1 and 3 .

Equilibrium. Considering the global equilibrium of the structure allows to write in the bay $\mathrm{i}$ the relationship between the adherend normal forces and the applied load:

$$
N_{1, i}+N_{2, i}=f
$$

The local equilibrium of both adherends in the bay i provides both following equations (cf. Figure 3):

$$
\begin{aligned}
& \frac{d N_{1, i}}{d x}=-b T_{i} \\
& \frac{d N_{2, i}}{d x}=b T_{i}
\end{aligned}
$$

Adhesive shear stress definition. A linear shear stress (thus strain) distribution through the thickness adherend is considered in the same way as described in [8]. Since zero shear stress state exists at the top surface of the upper adherend and at the bottom surface of the lower adherend, both adherend shear stresses are expressed as:

$$
T_{1, i}=\frac{y_{1}}{e_{1}} T_{i}
$$


$T_{2, i}=\left(1-\frac{y_{2}}{e_{2}}\right) T_{i}$

where $\mathrm{y}_{1}$ et $\mathrm{y}_{2}$ are local coordinates as defined in Figure 3.

The longitudinal displacements are then computed from the adherend shear stress by:

$$
\begin{aligned}
& u_{1, i} \varangle, y_{1} \fallingdotseq u_{1, i} \varangle, 0 \ni \int_{0}^{e_{1}} \frac{y_{1}}{e_{1}} \frac{T_{i}}{G_{1}} d y_{1}=u_{1, i} \varangle, 0 \text { Ð } \frac{1}{2} \frac{T_{i}}{G_{I}}\left(\frac{y_{1}}{e_{1}}\right)^{2} e_{1} \\
& u_{2, i} \lessdot, y_{2} \fallingdotseq u_{2, i} \varangle, 0 \text { ఫ } \int_{0}^{e_{2}}\left(1-\frac{y_{2}}{e_{2}}\right) \frac{T_{i}}{G_{2}} d y_{2} \\
& =u_{2, i} \ll, 0 \ni \frac{T_{i}}{G_{2}}\left(\left(\frac{y_{2}}{e_{2}}\right)-\frac{1}{2}\left(\frac{y_{2}}{e_{2}}\right)^{2}\right) e_{2}
\end{aligned}
$$

In order to compute the adhesive shear stress defined by:

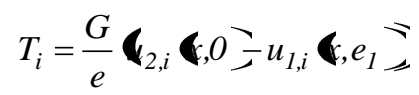

it is useful to express the longitudinal displacement of the upper adherend as:

$u_{1, i} \varangle, y_{1} \fallingdotseq u_{1, i} \varangle, e_{1}=\frac{1}{2} \frac{T_{i}}{G_{1}} e_{1}+\frac{1}{2} \frac{T_{i}}{G_{1}}\left(\frac{y_{1}}{e_{1}}\right)^{2} e_{1}$ 
since $\left(\mathrm{y}_{1}=\mathrm{e}_{1}\right.$ in Eqn. 6$)$ :

$u_{1, i} \varangle, e_{1} \fallingdotseq u_{1, i} \varangle, 0$ У $\frac{1}{2} \frac{T_{i}}{G_{1}} e_{1}$

Moreover, the average values of both adherend longitudinal displacements are given by:

$\bar{u}_{1, i} \lessdot \equiv \frac{1}{e_{1}} \int_{0}^{e_{1}} u_{1, i} \varangle, y_{1} \partial y_{1}=u_{1, i} \varangle, e_{1}=\frac{1}{3} \frac{T_{i}}{G_{1}} e_{1}$

$\bar{u}_{2, i} \uparrow \frac{1}{e_{2}} \int_{0}^{e_{2}} u_{2, i} \varangle, y_{2} \partial y_{2}=u_{2, i} \varangle, 0$ † $\frac{1}{3} \frac{T_{i}}{G_{2}} e_{2}$

Thus the adhesive shear stress can be expressed as:

$T_{i}=\frac{1}{1+\beta} \frac{G}{e} \leftarrow_{2, i} \Upsilon_{-}-\bar{u}_{1, i}$

where:

$\beta=\frac{1}{3} \frac{G}{e}\left(\frac{e_{1}}{G_{1}}+\frac{e_{2}}{G_{2}}\right)$ 


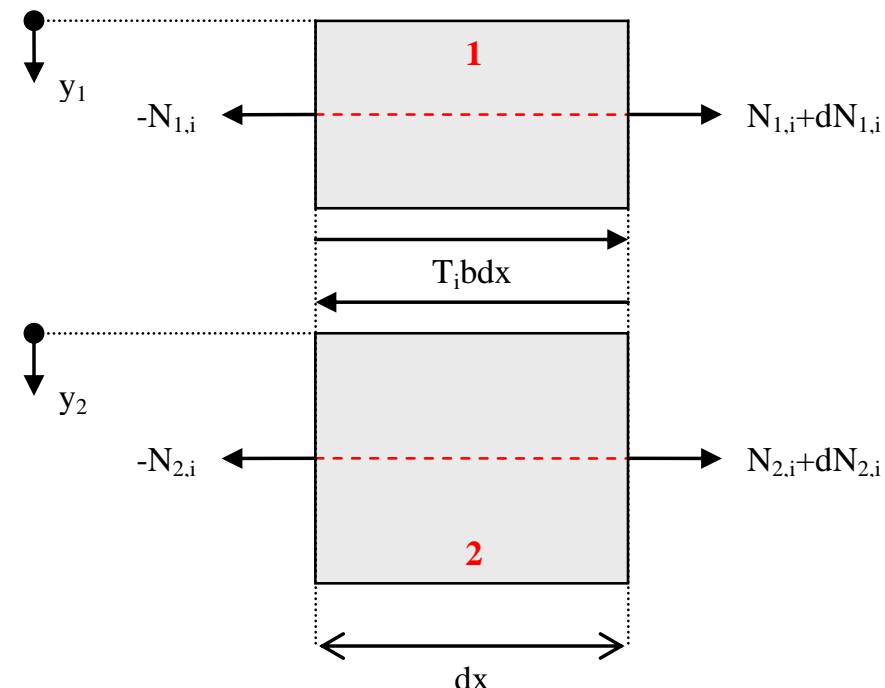

Figure 3: Local equilibrium of both adherends in the bay $\mathrm{i}$

Differential equation. The normal forces in the adherends are written as:

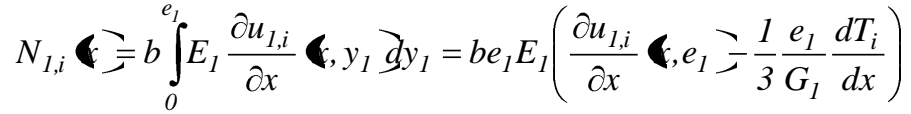

$$
\begin{aligned}
& N_{2, i} \lessdot b \int_{0}^{e_{2}} E_{2} \frac{\partial u_{2, i}}{\partial x} \varangle, y_{2} \partial y_{2}=b e_{2} E_{2}\left(\frac{\partial u_{2, i}}{\partial x} \ll, 0 \ni \frac{1}{3} \frac{e_{2}}{G_{2}} \frac{d T_{i}}{d x}\right)
\end{aligned}
$$

By differentiation of Eqn. 8, it comes with Eqn. 15 and Eqn. 16: 


$$
\begin{aligned}
\frac{d T_{i}}{d x} & =\frac{G}{e}\left(\frac{\partial u_{2, i}}{\partial x} \ll, 0=\frac{\partial u_{1, i}}{\partial x} \ll, e_{1}\right) \\
& =\frac{G}{e}\left(\frac{N_{2, i}}{b e_{2} E_{2}}-\frac{N_{1, i}}{b e_{1} E_{1}}-\frac{1}{3}\left(\frac{e_{1}}{G_{1}}+\frac{e_{2}}{G_{2}}\right) \frac{d T_{i}}{d x}\right)
\end{aligned}
$$

or:

$\frac{d T_{i}}{d x}=\frac{1}{1+\beta} \frac{G}{e}\left(\frac{N_{2, i}}{b e_{2} E_{2}}-\frac{N_{l, i}}{b e_{1} E_{1}}\right)$

The introduction of Eqn. 1 and Eqn. 3 in Eqn. 18 provides the following second order linear differential equation:

$\frac{d^{2} N_{i, 2}}{d x^{2}}-\eta^{2} N_{i, 2}=-\frac{\chi}{1+\beta} \frac{G}{e} \frac{1}{e_{2} E_{2}} f$

where:

$$
\begin{aligned}
& \eta^{2}=\frac{1}{1+\beta} \frac{G}{e}\left(\frac{1}{e_{1} E_{1}}+\frac{1}{e_{2} E_{2}}\right)=\frac{1+\chi}{1+\beta} \frac{G}{e} \frac{1}{e_{2} E_{2}} \\
& \chi=\frac{e_{2} E_{2}}{e_{1} E_{1}}
\end{aligned}
$$


Differential equation solution and boundary conditions. The solution of Eqn. 19 is under the shape:

$N_{i, 2}=A_{i} e^{-\eta x}+B_{i} e^{\eta x}-\lambda f$

where $\mathrm{Ai}$ and $\mathrm{Bi}$ are integration constants and:

$\lambda=-\frac{\chi}{1+\chi}$

Thus, using Eqn. 3, the adhesive shear stress is given by:

$T_{i}=\frac{\eta}{b}\left(A_{i} e^{-\eta x}+B_{i} e^{\eta x}\right.$

For each of the three bays, two integration constants have to be found. As a result six boundary conditions $\left(\mathrm{A}_{1}, \mathrm{~B}_{1}, \mathrm{~A}_{2}, \mathrm{~B}_{2}, \mathrm{~A}_{3}, \mathrm{~B}_{3}\right)$ are required.

The first boundary condition corresponds to a zero load at $\mathrm{x}=0$, which leads to:

$$
N_{2,1} Q=0 \Leftrightarrow A_{1}+B_{1}=\lambda f
$$

The second boundary condition corresponds to complete load transfer at $\mathrm{x}=\mathrm{L}$, which leads to: 


$$
N_{2,3} \mathbf{C} f \Leftrightarrow e^{-\eta L} A_{3}+e^{\eta L} B_{3}=\mathbf{Q}+\lambda I
$$

Two additional boundary conditions are given by considering the continuity of the shear stress at each of both fasteners:

$T_{1} \ggg T_{2} \Leftrightarrow e^{-\eta d} A_{1}-e^{\eta d} B_{1}-e^{-\eta \eta d} A_{2}+e^{\eta d} B_{2}=0$

$T_{2} \mathbf{C}-d \equiv T_{3} \mathbf{C}-d \xi e^{-\eta \mathbf{C}-d} \mathcal{A}_{2}-e^{\eta \mathbf{C}-d} B_{2}-e^{-\eta \mathbf{C}-d} \mathcal{A}_{3}+e^{\eta \mathbf{C}-d} B_{3}=0$

Both last boundary conditions are obtained by writing the load transfer at each of both fasteners:

$$
\begin{aligned}
& N_{2,2}=N_{2,1}+\tau_{1} f \\
& N_{2,3}\left(-d \equiv N_{2,2} \mathbf{c}-d+\tau_{2} f\right.
\end{aligned}
$$

But, the bolt load transfers are given by:

$$
\begin{aligned}
& \tau_{1} f=C_{f}\left(-\bar{u}_{1,1}\right) \\
& \tau_{2} f=C_{f}\left(\tau _ { 2 , 2 } \left(-d-\bar{u}_{1,2}(-d)\right.\right.
\end{aligned}
$$

By using the definition of the adhesive shear stress in Eqn. 13, the bolt load transfers are expressed under the shape: 
$\tau_{1} f=C_{f}\left(+\beta \frac{e}{{ }_{G}} T_{l}\right) \kappa\left(A_{l} e^{-\eta d}+B_{l} e^{\eta d}\right.$

$\tau_{2} f=C_{f}\left(+\beta \frac{e}{G} T_{2} \mathbf{C}-d \equiv \kappa\left(A_{2} e^{-\eta \mathbf{c}-d{ }^{2}}+B_{2} e^{\eta \mathbf{c}-d)}\right.\right.$

where:

$\kappa=\mathbf{\ell}+\beta \frac{e}{G} \frac{\eta}{b} C_{f}$

Both last boundary conditions are explicitly given using Eqn. 33 (Eqn. 34) in Eqn. 29 (Eqn. 30):

$$
\begin{aligned}
& q e^{-\eta d} A_{1}+r e^{\eta d} B_{1}-e^{-\eta d} A_{2}-e^{\eta d} B_{2}=0 \\
& q e^{-\eta(-d} \lambda_{A_{2}}+r e^{\eta(-d} B_{2}-e^{-\eta(-d} A_{3}-e^{\eta(-d} B_{3}=0
\end{aligned}
$$

where:

$q=1-\kappa$

$r=1+\kappa$

Finally, the integration constants are found by solving the following linear system: 


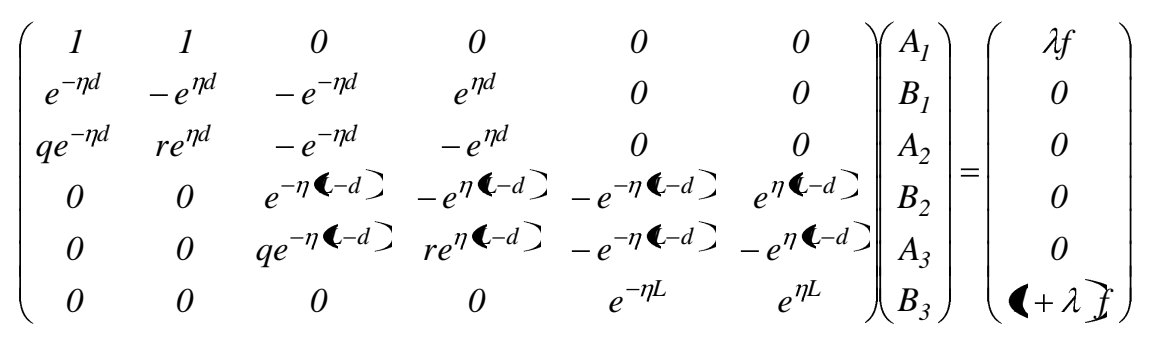

Resolution of the linear system for a balanced reference configuration. The system is solved in the case of a balanced reference configuration, leading to $\chi=1$ and thus $\lambda=-$ 0.5. The idealization then performed on the balanced reference configuration (cf. Figure 2) implies that both bolt load transfer rates are equal. This analytical model presented does not take into account possible imperfect geometrical and mechanical symmetry conditions. This additional condition allows for simplifying the resolution of the linear system, since only $A_{1}$ and $B_{1}$ have to be found, and provides the following equation:

$$
-e^{-\eta d} A_{1}+e^{\eta d} B_{1}=-e^{-\eta \boldsymbol{C}-d} \bar{A}_{2}+e^{\eta \mathbf{C}-d} B_{2}
$$

The linear system is then simplified in the following one: 


$$
\left(\begin{array}{cccc}
1 & 1 & 0 & 0 \\
e^{-\eta d} & -e^{\eta d} & -e^{-\eta d} & e^{\eta d} \\
q e^{-\eta \eta d} & r e^{\eta d} & -e^{-\eta d} & e^{\eta d} \\
e^{-\eta d} & -e^{\eta d} & -e^{-\eta \boldsymbol{C}-d}> & \left.e^{\eta \mathbf{C}-d}\right)
\end{array}\right)\left(\begin{array}{c}
A_{1} \\
B_{1} \\
A_{2} \\
B_{2}
\end{array}\right)=\left(\begin{array}{c}
-0.5 f \\
0 \\
0 \\
0
\end{array}\right)
$$

Then, by linear combinations, it comes:

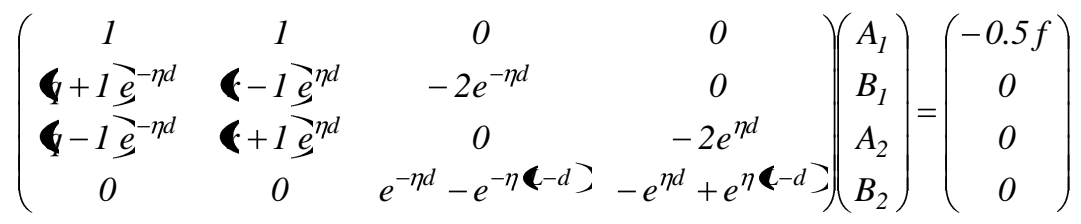

Finally, the six by six linear systems is reduced to the two by two linear system:

$$
\left(\begin{array}{cc}
1 & 1 \\
\tilde{q} e^{-\eta \eta d} & \tilde{r} e^{\eta d}
\end{array}\right)\left(\begin{array}{l}
A_{I} \\
B_{I}
\end{array}\right)=\left(\begin{array}{c}
-0.5 f \\
0
\end{array}\right)
$$

where:

$$
\begin{aligned}
& \tilde{q}=1-\cosh (\mathbf{c}-2 d)+\sinh (\mathbf{c}-2 d) \\
& \tilde{r}=-1+\cosh (\mathbf{c}-2 d \overline{-}-r \sinh (\mathbf{c}-2 d)
\end{aligned}
$$

Finally, $A_{1}$ and $B_{1}$ are given by: 
$A_{l}=\frac{1}{2} \frac{\tilde{r} e^{\eta d}}{\tilde{q} e^{-\eta d}-\tilde{r} e^{\eta d}} f$

$B_{1}=\frac{1}{2} \frac{\tilde{q} e^{-\eta d}}{\tilde{r} e^{\eta d}-\tilde{q} e^{-\eta d}} f$

Thus, by introducing Eqn. 47 and Eqn. 48 in Eqn. 33, the bolt load transfer is provided:

$\tau_{2}=\tau_{1}=\frac{1}{2} \kappa\left(\frac{\tilde{r}+\tilde{q}}{\tilde{r} e^{\eta d}-\tilde{q} e^{-\eta d}}\right)$

\section{Application on the reference configuration}

The above mentioned formula (Eqn. 49) of the bolt load transfer rate is applied to the reference configuration for various values of the adhesive Coulomb's modulus. The result is plotted in Figure 4 with a fastener stiffness equal to 50000 N.mm ${ }^{-1}$.

Results show that the bolt load transfer rate tends to zero when the adhesive stiffness increases, so that at high adhesive modulus the fasteners do not participate in the load transfer. The bonded joint and the bolted joint could be seen as both limit cases of the HBB joint. 


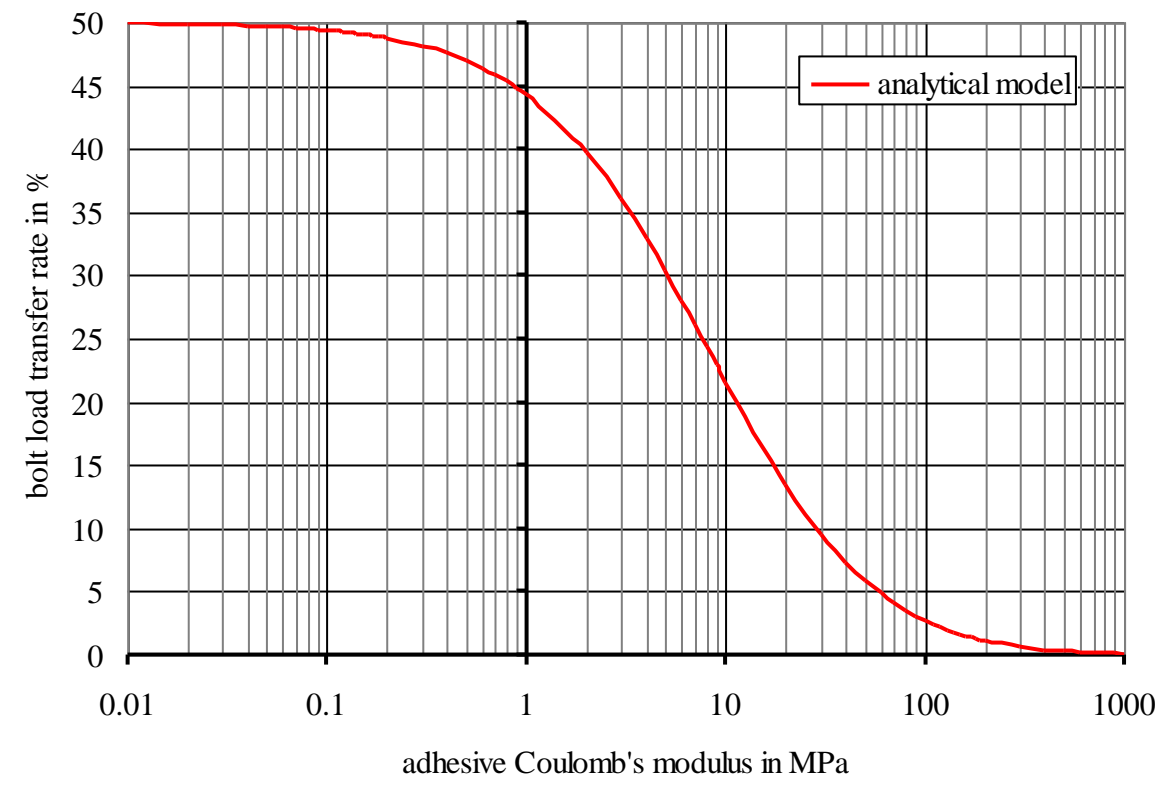

Figure 4: Bolt load transfer rate as a function of the adhesive Coulomb's modulus for the reference configuration

\section{THREE-DIMENTIONNAL FINITE ELEMENT ANALYSIS}

\section{Description of the analysis}

A $3 \mathrm{D} \mathrm{FE}$ analysis is performed on the reference configuration in order to interpret SCF as a function of the bolt load transfer rate;

This analysis aims at checking the possibility of fatigue life improvement of bolted joints thanks to the HBB joining technology. 


\section{Presentation of the model}

The developed model is fully detailed in [13] and is based on the model as presented in [8]. A brief description is given hereafter. The FE model is developed using threedimensional brick elements by using the SAMCEF FE code [14]. More precisely, the adherends are modelled with eight-node element (24 DoF), while the adhesive layer and the fasteners are modelled with twenty-node elements (60 DoF). The mesh around the holes and at the overlap ends is refined, in order to ensure the convergence of computations (see Figure 5).

An isotropic linear elastic behaviour of adherends and fasteners is considered, so that the applied stress is equal to $80 \mathrm{MPa}$. The adhesive layer is considered to be non linear elastic and quasi-incompressible; it is simulated by a two-coefficient $\left(\mathrm{C}_{10}\right.$ and $\mathrm{C}_{01}$ ) Mooney-Rivlin hyperelastic potential with a bulk modulus of $5000 \mathrm{MPa}$. The selective integration is employed to overcome the incompressibility problem.

Only a half of the joint is modelled using the symmetrical boundary condition. One end is clamped whereas the opposite end is free to move in the longitudinal direction only. No preload is applied to the fastener, and no clearance between the fasteners and the adherends is considered. The contact between the adherends and the fasteners is considered without friction. The geometrical non linearity is considered in the analyses.

The mechanical and geometrical parameters are given in Table 1 and Table 2. 


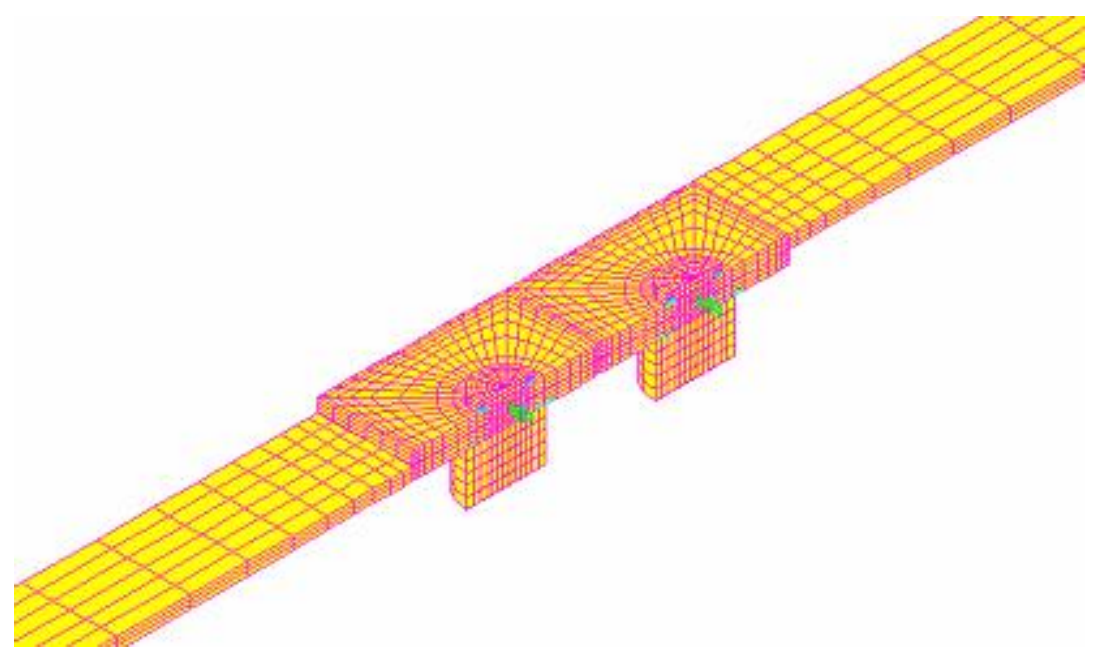

Figure 5: View of the mesh of the single-lap HBB joint

Measurement of the SCF as a function of the bolt load transfer rate

An equivalent adhesive Coulomb's modulus is defined as a function of both hyperelastic material parameters, $\mathrm{C}_{10}$ and $\mathrm{C}_{01}$, as:

$\mathrm{G}_{\mathrm{eq}}=2 \mathbf{C}_{10}+\mathrm{C}_{01}-$

In order to obtain different values of the bolt load transfer rate at the fixed geometry, the adhesive equivalent Coulomb's modulus is varied between 0.1 and $120.6 \mathrm{MPa}$ with respect to $\mathrm{C}_{01}=1.6 \mathrm{C}_{10}$. The bolt load transfer is numerically measured according 
to a special method developed in [4] and validated in [5], which consists in summing the nodal forces at the bolt mid-plane.

The stress concentration is computed as the ratio between the first principal stress, which is considered to be responsible for the initial crack, at the critical locations with respective applied stress.

The curves of the SCF as a function of the bolt load transfer rate measured for each of both bolts are given in Figure 6. It appears that the stress concentration factor varies almost linearly and increasingly with an increasing bolt load transfer rate, in a wide range of bolt load transfer rate included between around 5\% and $45 \%$.

By considering that the HBB joints are bolted joints for which all the applied load is transferred by the bolts, and with application of hypothesis $\mathrm{H} 2$, results show that the fatigue life performance of HBB joints are higher than bolted joints. 


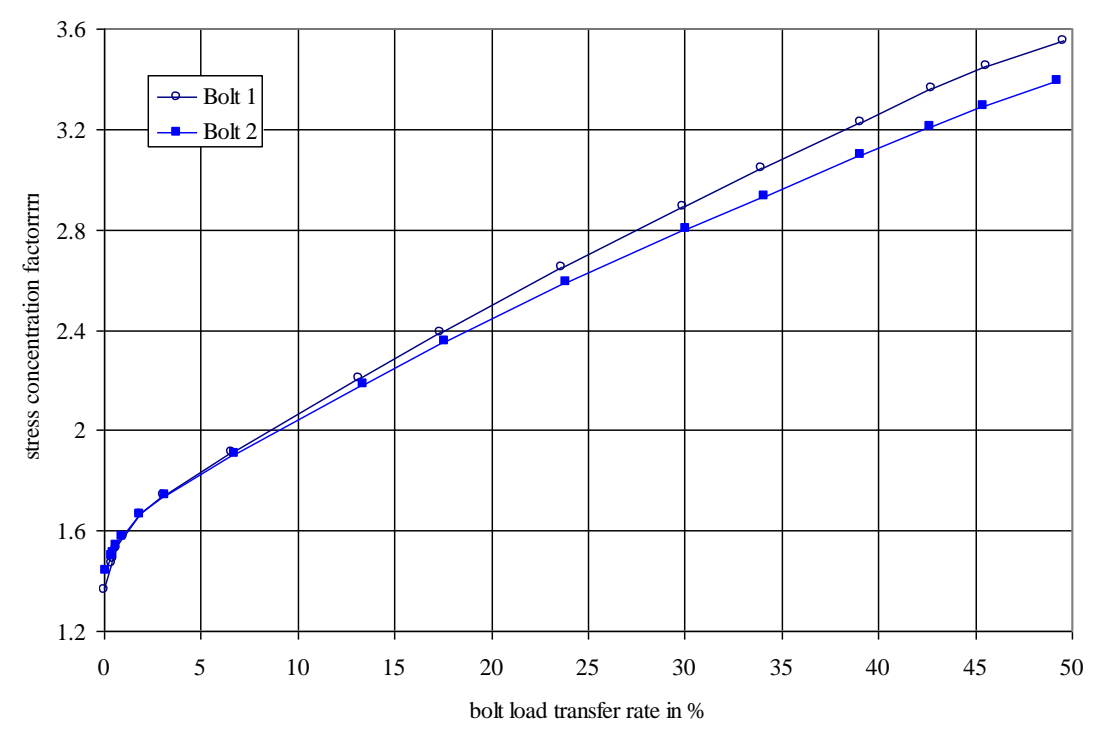

Figure 6: Stress concentration factor as a function of the bolt load transfer rate

\section{CONCLUSION}

In this study, with a three-dimensional FE analysis, a linear relation between bolt load transfer and SCF is demonstrated. Results also show improvement of fatigue life using HBB technology without increasing fastener lines. Here an onedimensional analytical approach is presented and applied for a particular case, in order to compute the bolt load transfer rate of HBB joints. The fastener stiffness could be considered as a parameter useful to calibrate the 1D model [5]. This calibration could be performed by finding the value of the fastener stiffness which 
minimizes the sum of the quadratic difference between the total load transferred by both fasteners computed by the analytical and the numerical approaches. On the reference configuration, the fastener stiffness is found equal to 29302 N.mm ${ }^{-1}$ (see Figure 7). This conclusion is sustainable under the hypothesis of critical sites located at the fastener lines and without considering any preload of fasteners.

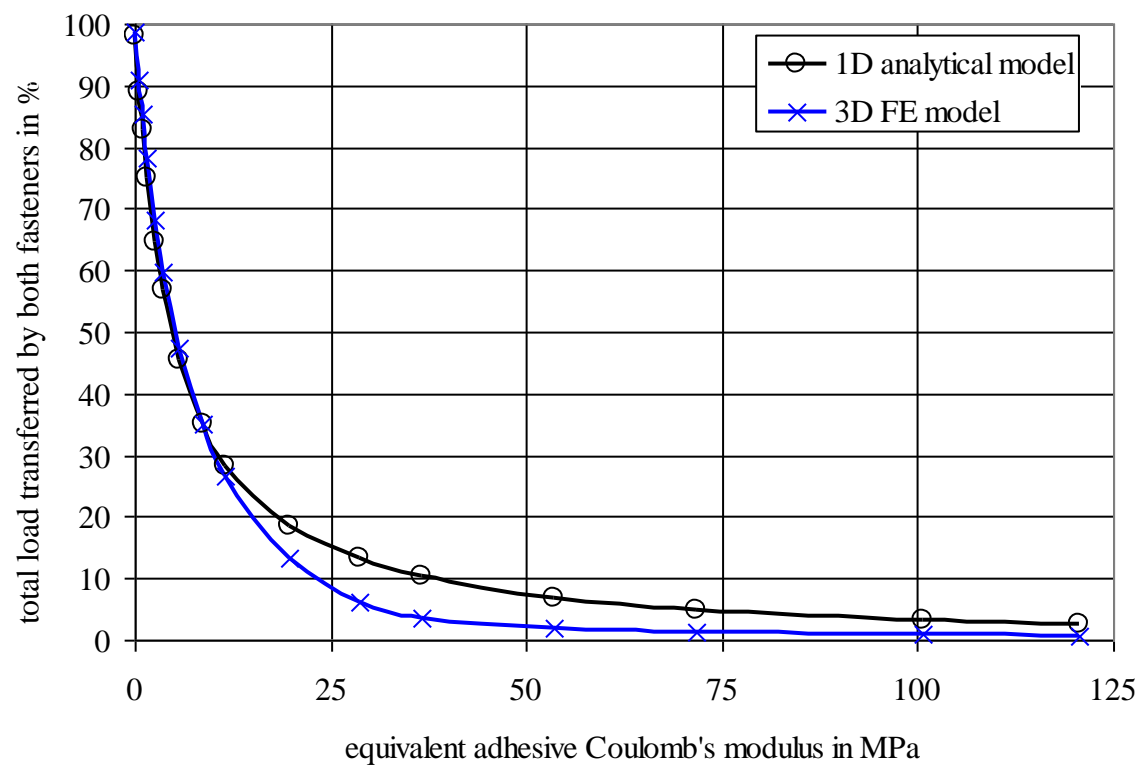

Figure 7: Comparison of the total load transferred by the fasteners computed by the $1 \mathrm{D}$ analytical model and the 3D FE model with $\mathrm{C}_{\mathrm{f}}=29302 \mathrm{~N} \cdot \mathrm{mm}^{-1}$ 


\section{NOMENCLATURE}

$\begin{array}{lll}\mathrm{A}_{\mathrm{j}} & \text { integration constant number j=1..3 } & {[\mathrm{N}]} \\ \mathrm{b} & \text { overlap width or transversal pitch } & {[\mathrm{mm}]} \\ \mathrm{B}_{\mathrm{j}} & \text { integration constant number j=1..3 } & {[\mathrm{N}]} \\ \mathrm{C}_{\mathrm{f}} & \text { fastener stiffness } & {\left[\mathrm{N} . \mathrm{mm}^{-1}\right]} \\ \mathrm{C}_{01} & \text { adhesive material parameter } & {[\mathrm{MPa}]} \\ \mathrm{C}_{10} & \text { adhesive material parameter } & {[\mathrm{MPa}]} \\ \mathrm{DoF} & \text { degree of freedom } & \\ \mathrm{e} & \text { adhesive thickness } \\ \mathrm{e}_{1} & \text { upper adherend thickness } & {[\mathrm{mm}]} \\ \mathrm{e}_{2} & \text { lower adherend thickness } & {[\mathrm{mm}]} \\ \mathrm{E}_{1} & \text { upper adherend Young's modulus } & {[\mathrm{mm}]} \\ \mathrm{E}_{2} & \text { lower adherend Young's modulus } & {[\mathrm{MPa}]} \\ \mathrm{f} & \text { in-plane applied force } & {[\mathrm{MPa}]} \\ \mathrm{FE} & \text { finite element } & {[\mathrm{N}]} \\ \mathrm{G} & \text { adhesive Coulomb's modulus } & {[\mathrm{mm}]} \\ \mathrm{G}_{1} & \text { upper adherend Coulomb's modulus } \\ \mathrm{G}_{2} & \text { lower adherend Coulomb's modulus } \\ \mathrm{HBB} & \text { hybrid (bolted/bonded) } & {[\mathrm{mm}]} \\ \mathrm{h}_{\mathrm{h}} & \text { height of fastener head } \\ \mathrm{h}_{\mathrm{n}} & \text { height of fastener nut } \\ \mathrm{l}_{1} & \text { upper outside the overlap length } \\ & & {[\mathrm{MPa}]} \\ & {[\mathrm{MPa}]} \\ & & {[\mathrm{MPa}]} \\ & \end{array}$


$1_{2}$ lower outside the overlap length $[\mathrm{mm}]$

$\mathrm{K}$ bulk modulus of the adhesive $\quad[\mathrm{MPa}]$

$\mathrm{K}_{\mathrm{t}} \quad$ stress concentration factor $\quad[-]$

L overlap length [mm]

$\mathrm{N}_{1, \mathrm{i}}$ upper adherend normal force in the bay $\mathrm{i}=1 . .3 \quad[\mathrm{~N}]$

$\mathrm{N}_{2, \mathrm{i}}$ lower adherend normal force in the bay $\mathrm{i}=1 . .3 \quad[\mathrm{~N}]$

$\mathrm{p} \quad$ longitudinal pitch $\quad[\mathrm{mm}]$

q characteristic parameter $\quad[-]$

$\tilde{q} \quad$ characteristic parameter $\quad[-]$

r characteristic parameter $\quad[-]$

$\tilde{r} \quad$ characteristic parameter $\quad[-]$

SCF stress concentration factor

$\mathrm{T}_{\mathrm{i}}$ adhesive shear stress in the bay $\mathrm{i}=1 . .3 \quad[\mathrm{MPa}]$

$\mathrm{T}_{1, \mathrm{i}} \quad$ upper adherend shear stress in the bay $\mathrm{i}=1 . .3 \quad[\mathrm{MPa}]$

$\mathrm{T}_{2, \mathrm{i}} \quad$ lower adherend shear stress in the bay $\mathrm{i}=1 . .3 \quad[\mathrm{MPa}]$

$\mathrm{u}_{1, \mathrm{i}} \quad$ upper adherend longitudinal displacement in the bay $\mathrm{i}=1 . .3 \quad[\mathrm{~N}]$

$\mathrm{u}_{2, \mathrm{i}} \quad$ lower adherend longitudinal displacement in the bay $\mathrm{i}=1 . .3 \quad[\mathrm{~N}]$

$\overline{\mathrm{u}}_{1, \mathrm{i}} \quad$ average value of $\mathrm{u}_{1, \mathrm{i}}$ through $\mathrm{e}_{1}$ in the bay $\mathrm{i}=1 . .3 \quad[\mathrm{~N}]$

$\overline{\mathrm{u}}_{2, \mathrm{i}} \quad$ average value of $\mathrm{u}_{2, \mathrm{i}}$ through $\mathrm{e}_{2}$ in the bay $\mathrm{i}=1 . .3 \quad[\mathrm{~N}]$

x structural rectangular Cartesian X-coordinate $\quad[\mathrm{mm}]$

y structural rectangular Cartesian y-coordinate $[\mathrm{mm}]$

$\mathrm{y}_{1}$ local rectangular Cartesian y-coordinate $\quad[\mathrm{mm}]$

$\mathrm{y}_{2}$ local rectangular Cartesian y-coordinate $[\mathrm{mm}]$ 


$\begin{array}{lll}\mathrm{z} & \text { structural rectangular Cartesian z-coordinate } & {[\mathrm{mm}]} \\ \beta & \text { characteristic parameter } & {[-]} \\ \chi & \text { characteristic parameter } & {[-]} \\ \kappa & \text { characteristic parameter } & {\left[\mathrm{mm}^{-1}\right]} \\ \lambda & \text { characteristic parameter } & {[-]} \\ \tau & \text { characteristic parameter } & {[-]} \\ \tau_{\mathrm{i}} & \text { bolt load transfer rate } & {[-]} \\ & \text { bolt load transfer rate of the fastener number i } \mathrm{i}=1,2 & {[-]}\end{array}$

\section{ACKNOWLEDGMENTS}

The authors gratefully acknowledge the engineers of the Methods and Research team of SOGETI High Tech Fatigue \& Damage Tolerance Department in Toulouse for their support and advice, in the frame of the development of JoSAT (Joint Stress Analysis Tool) internal research program.

\section{REFERENCES}


[1] Imanaka, M., Haraga, K., Nishikawa, T. (1995), Journal of Adhesion, vol. 49, pp. $197-209$

[2] Fu, M., Mallick, P.K. (2001), International Journal of Adhesion and Adhesives, vol. 21, pp. 145-159

[3] Kelly, G. (2006), Composites Structures, vol. 73, pp. 119-129

[4] Kelly, G. (2004), PhD Dissertation, KTH Aeronautical and Vehicle Engineering, Stockholm, SW

[5] Paroissien, E. (2006), PhD Dissertation (in French), 2006TOU30133, Institut de Génie Mécanique de Toulouse, FR

[6] Hart-Smith, L.J. (1982), Technical Report, AFWAL-TR-81-3154 vol. 1, Douglas Aircraft Company, Long-Beach, CA

[7] Paroissien, E., Sartor, M., Huet, J. (2007), Trends and Recent Advances in Integrated Design and Manufacturing in Mechanical Engineering II, Springer Eds., pp. $95-110$

[8] Paroissien, E., Sartor, M., Huet, J., Lachaud, F (2007), AIAA Journal of Aircraft, vol. 44, n. 2, pp. 573-582 
[9] Niu, M.C.-Y. (1999), Airframe Structural Design - Stress Analysis and Sizing, $2^{\text {nd }}$ Eds., Conmilit Press Ltd., Hong Kong

[10] Tsaï, M.Y., Oplinger, D.W., Morton, J. (1998), International Journal of Solids Structures, vol. 35, n. 12, pp. 1163-1185

[11] Tate, M.B., Rosenfeld N.J. (1946), Technical Note, n. 1051, National Advisory Committee for Aeronautics Washington, DC

[12] Ross, R.D. (1947), Technical Note, n. 1281, National Advisory Committee for Aeronautics Washington, DC

[13] Hoang Ngoc, C.T. (2008), Technical Note (in French), PE3/1190NT08/EP, Sogeti High Tech, Blagnac, FR

[14] SAMCEF, Ver. 11.1-04, $31^{\text {st }}$ August 2006, Samtech Group, Liège, BE 